\title{
20
}

\section{Support system for Chinese language teachers: a case of ITEM in support of teaching}

\author{
A.C.W. Fung and S.S. Hau \\ Department of Education Studies, Hong Kong Baptist University \\ Kowloon Tong, Hong Kong \\ Phone: (852)-23395679 \\ Fax: (852)-23397894 \\ e-mail: alexfung@hkbu.edu.hk \\ andyhau@ctsc.hkbu.edu.hk
}

\begin{abstract}
Educational administrators in future schools unavoidably will have to face the challenge presented by IT in education. They have to be concerned not only with systems for school management information, or for decision support and the like. They also need to be prepared to manage IT holistically for school improvement and effectiveness. The impact of IT on teaching and learning has to be included on the agenda. It is necessary therefore that the scope of ITEM encompasses the managing of IT systems for teaching and learning support, in addition to IT systems within the school office. This paper reports a case of developing a 'Chinese Language Teacher Support System' in Hong Kong. The process of the innovation is described, together with discussion on the outcome and the future prospects for such a system.
\end{abstract}

\section{Keywords}

Database, information technology, teaching support, teleconferencing

\section{INTRODUCTION}

The rapid development of information technology (IT) has increased the popularity of computerised school administration and management systems. The term 'ITEM' was coined for the area of 'Information Technology in Educational Management' at the first IFIP International Working Conference on the subject in Israel, 1994. Its appearance is gaining in frequency in writings related to school information systems (SISs), computeraided school administration (CASA), educational management information system (EMIS), and the like. In a broader perspective, as educational management would be meaningless when separated from teaching and learning, ITEM should have a place in 
issues related to curriculum, teaching, and learning activities where IT is, or can be, involved.

Gilmore (1995) has rightly observed that the focus of computers as a subject in itself in the educational field has been switched to their use as tools for learning and teaching. Transformational leaders in educational settings have to be aware that the impact of, for example, the Internet on education and schooling has only begun to appear as the tip of an iceberg. IT can do a lot more to support educational management and teachers, besides operational, administrative, and managerial processes.

This paper presents a case study of the development of a 'Chinese Language Teacher Support System' in Hong Kong. The concept of TSSs (Teacher Support Systems) where IT is used to support teaching is certainly not limited only to the subject of Chinese Language. A study by Gilmore (1995) shows that the use of computers in teaching increases teachers' confidence in addition to cognitive and social benefits for students. It is recognized that both CAL (Computer-aided Learning) and CAI (Computer-aided Instruction) have their importance in using IT directly in the learning and teaching process, but these are outside the scope of this paper. The focus of this paper is on a TSS that provides support and resource to teachers in their proactive planning in teaching.

\section{NETWORKS TO SUPPORT TEACHING AND LEARNING}

About a decade ago, the Education Department of South Australia set up a trial project, NEXUS, as an electronic information service to provide information to teachers and students (Leonard, 1990). NEXUS was later developed further to consist of electronic mailing, bulletin boards, and information databases. Users of the system can now share ideas of common interest, access materials and obtain experts' assistance through the network. Leonard (1990) remarks that schools are even willing to pay for the telecommunication service which can enhance the learning and teaching of their students. In the United Kingdom, the 'Campus 2000' project, launched in 1988, provides similar services of e-mailing, information retrieval, and teleconferencing to schools (Jones, 1990). In Israel, the Ministry of Education initiated in 1995 a pilot project "The Israeli Informatics Teachers' Net" to provide personal mail, bulletin boards, discussion groups, and information banks using the Internet for teachers (Barta et al., 1996). In Japan, the NEC corporation has set up its own in-house education system for staff development even using satellite communication (Kurat et al., 1990). These activities in different places reflect that there is a demand for on-line support in teaching and learning, as well as in staff development.

In Hong Kong, there are two TSSs currently in development and access to both is limited to teachers from selected schools. The first TSS network is 'TELENEX'; this was started by the Teaching of English Language Education Centre of Hong Kong University in 1994 in support of English language teaching (Tsui, 1994). The other is 'CLTSS', for teachers of Chinese language; this began only in April 1995 at the School Administration and Management System Training \& Research Unit of the Hong Kong Baptist University.

\section{THE CHINESE LANGUAGE TEACHER SUPPORT SYSTEM}

The CLTSS project is funded by the Language Fund of the Hong Kong Government. The Language Fund promotes research and development work in improving the 
language proficiency of people in Hong Kong. The aim of the CLTSS two-year project is to develop a computer-based information system network to support the teaching of Chinese language in local secondary schools. Technically the system is simply a computer network with a server at the support centre of the SAMS T\&R Unit which can be accessed by teachers with computers and modems at their schools. The content database in the server stores Chinese Language teaching resources for secondary classlevels one to seven, including standard reading passages, teaching plans, teaching ideas, learning tasks, and test papers. Such contents, however, are not materials centrally developed by language experts. They are materials collected from front-line teachers in the schools. The CLTSS, in other words, serves as a pool of teachers' materials, experience, and expertise that are in the field. The system is basically only using IT as a tool to help with the sharing and dissemination of such valuable teaching resources. This may be a characteristic of the CLTSS which in a way distinguishes it from other similar networks.

\section{CLTSS Project Management}

Two aspects of the project are described in the following sections. The first focuses on 'user-participation' and linking up with schools and teachers. The second concerns the technical part of the system, including hardware and system design and development.

\subsection{Link up with Schools and Teachers}

The link up here refers to the 'soft' side of the connection with the people to be involved in the project. It is well recognised that user-participation and involvement are necessary elements to the success of the innovation. Getting commitment from school heads and teachers was the very first step taken care of in project. In view of the limited resources and capacity of the research team, only schools within one district in Hong Kong (the Tsuen Wan, Kwai Chung and Tsing Yi district with 43 secondary schools) were targeted. A lunch seminar was held for the principals and Chinese language department heads of the schools in that district to explain and discuss the project objectives and the contributions required from the schools to be involved. In the subsequent week the schools interested in joining replied to the research team after their internal discussion and decision. Twenty-three schools volunteered to join the scheme, which then began in May 1995.

Ten schools out of the twenty-three were chosen as a core group and the rest serve as support schools in the project. The distinction was only a matter of resource in that schools in the core group could each be given a set of computer, modem, and telephone line. Owing to the budget limitation in the project, the support schools did not receive these hardware items. Both groups of school, however, have to contribute teaching resources in Chinese language to be stored in the server located at the project centre. It has to be pointed out that, in this regard, the project has made an initial breakthrough in attempting to pool teachers' resources, because there is no such culture of sharing teaching resources among teachers in Hong Kong, not to say across different schools. The concept of the teacher as a continuous learner, the school as a learning organisation, and schools in the project as a learning network was 'sold' to the participants in the above-mentioned seminar and apparently it had some effect. At a later stage of the project, it is planned that the number of participating schools will be expanded to forty across the Territory.

In two subsequent meetings with representatives of the ten core schools, further details about the project were attended to - the vision, the benefits, communication structure and methods. The teachers understood that CLTSS is to be a joint venture, and not a 'centre-to-periphery' project where experts design and develop resources for users. 'Ownership' of the system is thus shared between researchers and participants. When successfully implemented, teachers can share their own teaching resources with others 
and learn from one another how to improve their teaching in Chinese language. They can be more efficient and effective in preparing their lessons, learning tasks and activities, compare notes, review past examination papers of others, and also get advice from colleagues or even professionals in higher education institutes. With such a support system, insights and creative ideas can be generated and teachers' professionalism will also be enhanced. Using CLTSS, teachers can also save up more time to work on their teaching methods, and to attend to individual student needs. Hopefully, the standard of students' Chinese language proficiency will be improved in the long run. This form of shared-effort can also create a bond between teachers with mutual support to meet new challenges in the currently quite turbulent Hong Kong education system. Support is a great sign of encouragement and relieves teaching stress. This may be more apparent among new teachers than experienced ones, and department heads equipped with CLTSS will be in a better position to help their colleagues in professional development.

\subsection{Design and Development of CLTSS}

Five teachers were identified as key people from the ten core schools. They took up the three major roles of (1) linkage with teachers in the twenty-three schools in collecting of teaching resources; (2) selection of materials to be stored in the system; and (3) feedback on the design and development of the software as to user-friendliness and integrativeness. While technical views are important in system design, experience of these front-line teachers are found to be most valuable in determining the user requirements, what contents to be included and how these should be categorised. Without such collaborative participation by the involved teachers, it would not have been possible to achieve any success with CLTSS - nor perhaps with any other system.

Most of the materials collected so far from the twenty-three schools are paper documents, with a small portion only in word-processed format. This reflects the fact that many Chinese Language teachers in Hong Kong are not yet accustomed to wordprocessing. Quite a lot of effort has been spent by the CLTSS support-centre to key-in the materials for the content database.

A system study was carried out in April 1995 and it was decided that a prototype should be produced as soon as possible for the ten core schools. Design and layout for the prototype were discussed with the five key teachers, and revised accordingly. Programming for this tailor-made prototype was completed in July 1995 and it was installed in the schools of the five key teachers for testing. The prototype consisted of a local searching system, and a connection facility to the CLTSS-database at the supportcentre where five data lines had been installed.

The prototype provided a number of functions :

(A) Local operation -

Materials that have been inputed in digital form are classified into different categories of data for teaching or reference purpose. This forms the 'contentlibrary' (see below) in the server at the support-centre, but a subset of the core content is duplicated also and stored as a database in the computer at each school. Teachers can search and retrieve from the local database documents they are interested in.

(B) Dial-up operation -

Functions provided under this category are commonly found on BBSs (Bulletin Board Systems) including E-mail, Teleconferencing, Special Interest Groups (SIGs are the same as discussion groups), and Information Exchange (for public messages from the centre to teachers, and vice-versa). In addition to these, a 'Content-Library' with all teaching resources currently available at the centre can be accessed. The data-set in this is bigger than that in the local drives at the schools. 
Searching and retrieval from the Content-library is the same as from the local drive, except that the response and download time is longer.

There are several reasons behind the strategy adopted in the prototyping, with both local and dial-up operations. Firstly, as there were no suitable Chinese BBSs on hand at the time, it was necessary to use one operating on MS-DOS which was 'satisfying' only in terms of ease-of-use and response time. Secondly, to create early success in the project, the system had to provide users with some return in the shortest time possible; and this could be achieved through the use of the local database installed. Thirdly, the prototype also provided teachers an opportunity to learn about CLTSS, in preparation for future updates.

The CLTSS prototype was put into all the ten core schools in mid-October 1995, after testing by the five key teachers and with some minor modifications. By 31 December 1995, 68 teachers had registered as users and the system had answered 1,090 calls, accumulated 460 files uploaded and 483 files downloaded. This is on top of the local usage at the ten individual schools. (This local usage was not counted because it was only prototyping.) During that period of only two months in which two weeks were school holidays, 1,300 messages were exchanged including public messages and private e-mails.

Development continued on the content database and by the end of December, 15 different categories of teaching resource were built with a total of 372 files. However, the response time was, as anticipated by the system designers, not up to users' expectations. Fortunately a new Chinese BBS that operates on the Windows platform had already been identified and the prototype was superseded by the first regular version of CLTSS in April 1996. With this Windows-based version, even teachers with little computer experience will be able to make use of CLTSS more comfortably, and the response time has been demonstrated to be much faster than that with the prototype.

\section{CONCLUSION}

Much time and effort is required unavoidably in setting up a teaching support system. But such efforts will be rewarded in the longer term with time-savings on the teachers' part, with professional growth, and with improvement in teaching and learning effectiveness. Despite the explosion of information technology, there are teachers who are still using index cards and stencils, and who are still hesitant to follow the trend of information technology. Psychological effects and technical support are issues that can never be ignored. As Fung (1995) has said,

"It would be very wrong to assume that given the hardware and software, information technology can be implemented into educational settings with automatic success. Using information technology in educational management, ITEM, irrespective of scope or scale, is an innovative process which needs managing." (p. 37)

With the advent of the Internet, the next phase of development for the CLTSS is naturally linkage to the World Wide Web. Besides development of the system, it is also planned that an evaluation research on the use of the system (e.g. the impact on the teaching behaviour of users) will be done. Although schools in Hong Kong are not currently provided by the government with the facility to access the Internet, it is likely that such access will be provided soon. The technology for building Chinese websites is 
already there; it is only a matter of time and resources before schools across and outside of Hong Kong would be able to login to a CLTSS website - with hypertexts and multimedia capabilities. It is also anticipated that similar websites for different subjects will be built in future, and such teacher-support systems will help to improve teaching and learning by the students in the schools.

\section{REFERENCES}

Barta, B.Z., Salant, A. and Telem, M. (1996) Internet support to school innovation management, in Proceedings of the 2nd IFIP International Working Conference on ITEM, Hong Kong Baptist University, Hong Kong.

Fung, A.C.W. (1995) Managing Change in ITEM, in Information Technology in Educational Management (eds. B.Z. Barta et al.), Chapman \& Hall, London.

Gilmore, A.M. (1995) Turning teachers on to computers: evaluation of a teacher development program. Journal of Research on Computing in Education, 27(3), 251269.

Jones, G. (1990) Communication for the curriculum, in Proceedings of the IFIP TC3 Fifth World Conference on Computers in Education, 983-987.

Kurata, M., Maekawa, Y., Nomura, Y., Matsushita, S., Inotsume, K. and Ohtake, Y. (1990) A networking educational system with NESPAC, in Proceedings of the IFIP TC3 Fifth World Conference on Computers in Education, 997-1002.

Leonard, R. (1990) Nexus III - Telecommunications beyond the classroom, in Proceedings of the IFIP TC3 Fifth World Conference on Computers in Education, 1003-1008.

Tsui, A. (1994) The participant structures of TeleNex: a computer network for ESL teachers. Paper presented at the International Language in Education Conference, Hong Kong.

\section{BIOGRAPHIES}

Alex C.W. Fung received a B.Sc. in 1970 from the University of Hong Kong and Cert.Ed., Adv.Dip.Ed., and M.Ed. in subsequent years from the same university. He received his Ph.D. in educational management and administration in 1992 from the London University Institute of Education. He was a secondary school principal in Hong Kong for more than twenty years before he joined the Department of Education Studies of the Hong Kong Baptist University as senior lecturer in 1994. He is currently an associate professor and also Director of the School Administration and Management System Training \& Research Unit at the Hong Kong Baptist University.

S.S. Hau received a B.Sc. in 1989 from St. Francis Xavier University, Canada. He has been working in the Information Technology industry for 6 years. He is currently an M.Phil student in the Department of Education Studies of Hong Kong Baptist University. 